\title{
Non-Ionizing Radiation around Tanning Beds
}

\author{
Bahriye Sirav $^{1 *}$, Nesrin Seyhan ${ }^{1}$
}

\begin{abstract}
Objective: Use of artificial tanning devices that emit UV radiation, such as tanning lamps and tanning beds, has become increasingly popular in the world. A tanning bed is a device emitting ultraviolet radiation used to produce a cosmetic tan. A number of studies have been conducted evaluating the risk of cutaneous malignant melanoma after exposure to sunlamps and/or sunbeds. Although an excess risk of nonmelanoma skin cancers might be predicted from this exposure, little epidemiologic data exist.
\end{abstract}

Material and Methods: In this study the leakage electromagnetic fields around artificial tanning devices were measured in Sun Club Beauty Salon and Solarium in Ankara, Turkey and evaluated in terms of standards.

Results: It has been observed that operators exposed to low ELF and RF fields with respect to general public and occupational exposure limits. However, global health experts have moved use of sunbeds and exposure to ultraviolet radiation (including sun exposure) to the highest risk category for causing cancer.

Conclusion: They now join agents such as tobacco, asbestos and benzene in being classed as "carcinogenic to humans" whereas before they were classed as "probably carcinogenic". Precautions should therefore be taken to minimise the exposed fields.

Keywords: Tanning beds, Radio Frequency Radiation, Extremely Low Frequency, Exposure Limits

\section{Introduction}

Solar radiation is the main source of human exposure to ultraviolet (UV) radiation, which is further subdivided into UVA, UVB, and UVC. The ultraviolet component that reaches the earth's surface comprises around 95\% UVA and 5\% UVB; UVC is blocked by stratospheric ozone. The use of UV-emitting tanning devices is widespread in many developed countries, especially among young women. Overexposure to ultraviolet radiation is known to cause skin cancer, make skin age and wrinkle faster, mutate DNA, and reduce the immune system. Frequent tanning bed use triples the risk of developing melanoma, the deadliest form of skin cancer. A tanning bed is a device emitting ultraviolet radiation (typically 97\% UVA and $3 \%$ UVB) used to produce a cosmetic tan. Regular tanning beds use several fluorescent lamps that have phosphor blends designed to emit UV in a spectrum that is somewhat similar to the sun. Smaller, home tanning beds usually have 12 to 28100 watt lamps while systems found in salons can run from 24 to 60 lamps, each consuming 100 to 200 watts.

Because of the adverse effects on human health of overexposure to UV radiation, including skincancer, cataracts, suppression of the immune system, and premature skin aging, the World Health Organization does not recommend the use of UV tanning devices for cosmetic reasons (1).
In fact, most tanning beds emit mainly UVA rays which may increase the risk of melanoma, the deadliest form of skin cancer. Using a sunbed without glasses may also lead to a condition known as arc eye.

The effects of extremely low frequency (ELF) magnetic and electric fields and radio frequency (RF) electromagnetic fields on the biological organisms have been investigated at Biophysics Department of Gazi University since 1990. The effects of $50 \mathrm{~Hz}, 0.2$ $\mathrm{mT}-3 \mathrm{mT}$ magnetic field exposures on collagen synthesis, epilepsy, electrolytes, lipid peroxidation (MDA), Nitric Oxide (NOx), respiratory burst system (MPO), antioxidant defense system (GSH), and immune system in spleen, skin, lung, kidney, brain and plasma tissues have been evaluated and these studies indicate that ELF magnetic fields have significant effects on these tissues (2-6).

Effects of static and $50 \mathrm{~Hz}$ ELF electric (E) fields on free radical synthesis, antioxidant enzyme level, and collagen synthesis were also analyzed on tissues of guinea pigs, such as brain, liver, lung, kidney, spleen, testis and plasma (7-10)

The results indicate that the effects of E fields on the tissues depend on the type and magnitude of the field and exposure period. 
Evaluation of RFR (Radio Frequency Radiation) in a chosen pilot area, Yenimahalle Şentepe - Dededoruk Hill in Ankara, was realized first time in Turkey in 2001 by Gazi Biophysics. RF radiation at that region, which have 64 different TV and radio towers and one base station, was found 4 times higher than the permitted standards of Turkey. The base station and some of TV and radio transmitters were not included in the calculations, since their technical information were not available (11). RF at non-thermal levels could have significant effects on the permeability of blood-brain barrier $(12,13)$. The effect of mobile phone radiation at different frequencies and strengths and the effects of radio frequency radiation on tissue hydroxyproline level were studied (14). Mobile phone exposure based RF dosimetry was determined by using FDTD method (15). The ongoing study on RFR is the effect of mobile-phone like radiation on pregnant animals and their infants. It has been recently reported that the distortion product autoacoustic emissions in infant rabbits are affected by mobile phone radiation (16). In the Biophysics Department, a Gazi Non-Ionizing Radiation Protection (GNRP) Center was founded in 2005. This Center performed studies on the biological effects of electromagnetic radiation and other studies mapping residential and workplace electromagnetic field levels since its foundation. GNRP also deals with training programmes on non-ionizing radiation, protection from non-ionizing radiation and electromagnetic fields consultancy. The Centre has also reported measurements of high electromagnetic field strengths. After these measurements, counseling and training programmes for public / workers were recommended by GNRP.

The biological effects of exposure to RF and microwave radiation have been studied extensively and have been well reviewed by several national and international bodies (17). Currently there is no study that presents the measured electromagnetic fields, especially extremely low frequency fields and radio frequency electromagnetic radiation from tanning beds. The annual rate of about 2000 deaths from skin cancer in Germany, are mainly caused by extensive exposure to solar UV radiation, demands protective measures (18).

\section{Materials and Methods}

Five tanning units have been identified in Sun Club Beauty Salon and Solarium Centre. Three of them are running. The models of devices are Ergoline Solarium, Ergoline 2 and Ergoline 600. Third one was being used while measurement, so it could not be measured. First system included 46 lamps with $160 \mathrm{~W}$ to burn the body and 3 lamps with $500 \mathrm{~W}$ to burn the face. Manufacturer mentioned in the catalog that total energy consumption is $13.7 \mathrm{~W}$. Compensation is compulsory for the center due to high energy consumption. Due to this consumption, the fire risk is very high in the building where many people live and / or work there. Field-strength measurements were made in the absence of the human but at the normal location to demonstrate that the measured value was below the appropriate guideline level or vice versa. With this aim, exposed RF electric field levels were measured with EMR 300 (Narda, Pfullingen, Germany) and appropriate probes at 4 points (mentioned in the figure with square frame) around the dielectric heater in Sun Club Beauty Salon and Solarium (Fig. 1). EFA 300 (Narda, Pfullingen, Germany) was also used to measure the ELF magnetic fields at 7 points (shown in the circles in the figure).

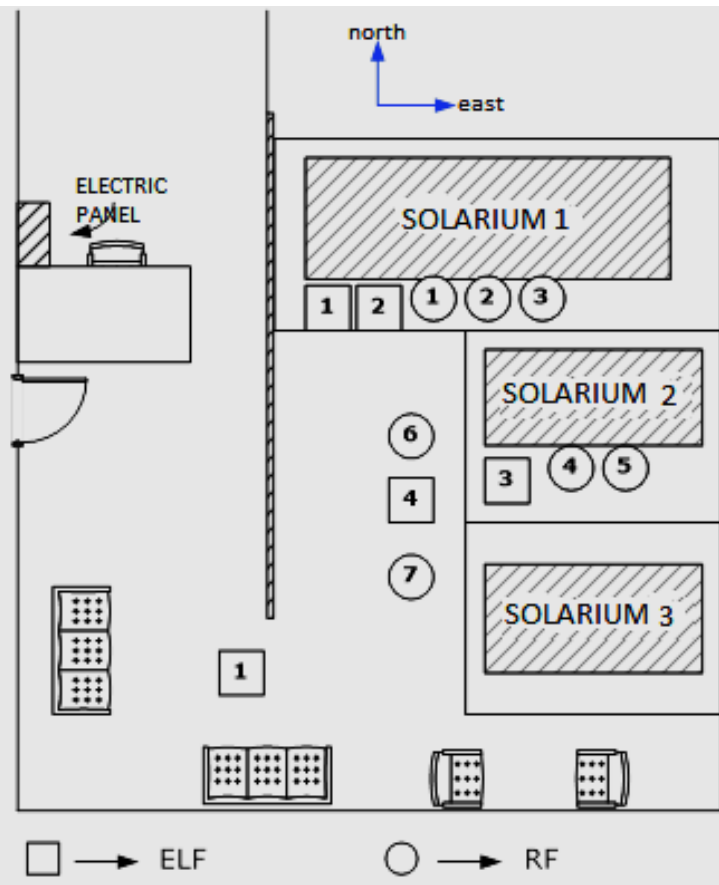

Figure 1: Electromagnetic Field Measurement points in the Solarium Center

International Commission on Non-Ionizing Radiation Protection (ICNIRP) provides a two-tier set of electromagnetic field exposure limits (19). The higher tier is referred to as Occupational while the more restrictive tier is referred to as General Population. Turkey's limits for the electric and magnetic field, which was formed by Turkish Information and Communication Technologies Authority (ICTA) in collaboration with Gazi Biophysics, are identical with the ICNIRP standards (20).

There are only differences in two points: Turkey's limits are available for only general public and the frequency range for Turkey's limits is $10 \mathrm{kHz}-60$ $\mathrm{GHz}$. In this study, measurement results were compared with ICNIRP occupational and general public exposure limits mentioned Table 1 for $10 \mathrm{MHz}$ - $100 \mathrm{MHz}$ frequency range. Table 2 represents the occupational and general public ICNIRP $50 \mathrm{~Hz}$ magnetic field limits and IARC's threshold for ELF magnetic fields. 
Table 1. ICNIRP Occupational and General Public exposure limits for 10-100 MHz (19)

\begin{tabular}{lccc}
\hline Category & $\mathbf{E}$ & $\mathbf{H}$ & $\mathbf{B}$ \\
& $(\mathbf{V} / \mathbf{m})$ & $(\mathbf{A} / \mathbf{m})$ & $(\boldsymbol{\mu} \mathbf{T})$ \\
\hline Occupational Exposure & 61 & 0.16 & 0.2 \\
General Public Exposure & 28 & 0.073 & 0.092 \\
\hline
\end{tabular}

Table 1. ICNIRP Occupational and General Public exposure limits for 10-100 MHz (19)

\begin{tabular}{lccc}
\hline Category & $\mathbf{E}$ & $\mathbf{H}$ & $\mathbf{B}$ \\
& $(\mathbf{V} / \mathbf{m})$ & $(\mathbf{A} / \mathbf{m})$ & $(\boldsymbol{\mu T})$ \\
\hline Occupational Exposure & 61 & 0.16 & 0.2 \\
General Public Exposure & 28 & 0.073 & 0.092 \\
\hline
\end{tabular}

Table 3. Measured ELF magnetic $(\mathrm{H})$ fields

\begin{tabular}{|c|l|c|c|}
\hline No & \multicolumn{1}{|c|}{ Measurement point } & Magnetic field (mG) & Frequency (Hz) \\
\hline $\mathbf{1}$ & Solarium 1 off, inside the unit & 1,09 & 33 \\
\hline $\mathbf{2}$ & Solarium 1 on, inside the unit & $\mathbf{5 2 , 0 8}$ & 51 \\
\hline $\mathbf{3}$ & Solarium 1 on, in front of the unit & $\mathbf{9 , 3 4}$ & 51 \\
\hline $\mathbf{4}$ & Solarium 2 on, inside the unit & $\mathbf{1 0 , 5 8}$ & 151 \\
\hline $\mathbf{5}$ & Solarium 2 on, in front of the unit & 1,94 & 131 \\
\hline $\mathbf{6}$ & Solarium 1,2 and 3 on, in front of the 2nd unit & 0,93 & 51 \\
\hline $\mathbf{7}$ & Solarium 1,2 and 3 on, in front of the 3rd unit & 1,05 & 51 \\
\hline
\end{tabular}

Table 4. Measured RF electric fields $(100 \mathrm{kHz}-3 \mathrm{GHz})$

\begin{tabular}{|c|l|c|c|c|}
\hline No & \multicolumn{1}{|c|}{ Measurement point } & $\begin{array}{c}\text { Max } \\
(\mathbf{V} / \mathbf{m})\end{array}$ & $\begin{array}{c}\text { Average } \\
(\mathbf{V} / \mathbf{m})\end{array}$ & $\begin{array}{c}\text { Max. Av. } \\
(\mathbf{V} / \mathbf{m})\end{array}$ \\
\hline $\mathbf{1}$ & Solarium 1 off, room RF field & 0,94 & 0,04 & 0,08 \\
\hline $\mathbf{2}$ & Solarium 1 on, around the unit & 2,64 & 0,13 & 0,64 \\
\hline $\mathbf{3}$ & Solarium 2 on, around the unit & 0,49 & 0,05 & 0,05 \\
\hline $\mathbf{4}$ & Solarium 1,2 and 3 on, the whole salon measurement & $\mathbf{5 , 1 3}$ & 0,37 & 0,44 \\
\hline
\end{tabular}

Results and Discussion

Measured ELF magnetic fields are given in Table 3. Bold values are magnetic field levels higher than IARC threshold which was announced for the threshold level for childhood leukemia (22). Other values were well below than the limits.

Measured RF electric fields are given in Table 4. EMR 300 measures electromagnetic fields in three mode; maximum, average and maximum average modes. According to electromagnetic field measurement techniques (19), average mode electromagnetic field levels should be used in analyzing exposure. In Table $\mathbf{4}$, bold value shows the maximum field level. When the average electric and magnetic field levels were compared with ICNIRP 1998 general public limits $(28 \mathrm{~V} / \mathrm{m}-0.073 \mathrm{~A} / \mathrm{m})$ and occupational exposure limits $(61 \mathrm{~V} / \mathrm{m}-0.16 \mathrm{~A} / \mathrm{m})$, it can be seen that people exposed to low electric fields than general public limits. First Non-Ionizing Radiation Protection Center of Turkey - Gazi NonIonizing Radiation Protection (GNRP) Center has been founded by Biophysics Department of Gazi University Faculty of Medicine in Ankara on July, 22, 2005. GNRP has been working on electromagnetic field measurements and counseling activities about Non-Ionizing Radiation (NIR) since its foundation. One of the most important activities of GNRP was Sun Club Beauty Salon and Solarium measurement.

The effects of RF in humans and exposed field levels are still emerging area of investigation. In this measurement study it has been observed that measured average levels of RF electric fields for the center are under the order of occupational and general 
public exposure limits. Results showed that ELF magnetic field measurement values also could be announced as safe. However when compared with the IARC's threshold levels based on childhood leukemia epidemiologic studies (22), it can be seen that people are exposed to ELF magnetic fields higher than the limit. Studies on women in workplaces suggest breast cancer for long term exposures to $10 \mathrm{mG}$ and higher. Magnetic field levels measured in this study are also in the order of breast cancer thresholds.

The US Public Health Service states that UV radiation, including the use of sun lamps and sun beds are "known to be a human carcinogen" (24). An IARC Working Group has classified UV-emitting tanning devices as "carcinogenic to humans" (Group 1). Combined analysis of over 20 epidemiological studies shows that the risk of cutaneous melanoma is increased by $75 \%$ when the use of tanning devices starts before age 30 . There is also sufficient evidence of an increased risk of ocular melanoma associated with the use of tanning devices. Studies in experimental animals support these conclusions and demonstrate that ultraviolet radiation (UVA, UVB, and UVC) is carcinogenic to humans. These findings reinforce current recommendations by the World Health Organization to avoid sunlamps and tanning parlours and to protect people from overexposure to the sun.

A comprehensive meta-analysis concluded that the risk of cutaneous melanoma is increased by $75 \%$ when use of tanning devices starts before 30 years of age (). Additionally, several case-control studies provide consistent evidence of a positive association between the use of UV-emitting tanning devices and ocular melanoma (25).Therefore, the Working Group raised the classifi cation of the use of UVemitting tanning devices to Group 1, "carcinogenic to humans" (26).

There is scientific evidence that each of the three main types of skin cancer, basal cell carcinoma (BCC), squamous cell carcinoma (SCC) and melanoma, is caused by UV exposure (27). Women who visited a tanning parlor at least once a month were $55 \%$ more likely to later develop melanoma than women who didn't artificially suntan. Young women who used sun lamps for tanning while in their 20s had the largest increase in subsequent cancer risk - about $150 \%$ higher than similar women who did not use tanning beds. Overexposure to ultraviolet radiation induces at least two common genetic mutations. Those include cyclobutane-pyrimidine dimers (CPDs) and 6-4 photoproducts (6-4PPs) and their Dewar valence isomers (28). The mutation types generally differ between UVA and UVB light (29). The basal layer in human squamous tumors harbors more UVA than UVB fingerprint mutations: A role for UVA in human skin carcinogenesis. Mutant cells may die, or become cancerous, depending on which genes were mutated. While DNA repair enzymes can fix some mutations, they are not sufficiently effective, as demonstrated by the relation to cancer, aging and other types of persistent mutation and cell death. For example, squamous cell carcinoma is caused by a UVB induced mutation in the p53 gene (28).

UVA light is clearly associated with increased skin aging and wrinkle production. This is because UVA penetrates the skin more deeply than UVB, and therefore causes damage on a deeper level. Most aging of skin is due to UVA rays destroying collagen and connective tissue beneath the superficial layer of the skin. UVB rays do not reach as far below the skin. Excessive exposure to UVA radiation has its risks, which may cause premature aging, including wrinkles, sunspots, and loss of skin elasticity (30).

The European Union is discussing new regulations that would limit the amount of UVB allowed in tanning lamps and devices. The Province of Ontario, Canada, is also considering introducing regulations obliging tanning salons to post warning labels on the beds informing consumers of the risks of skin cancer due to indoor tanning. They are also considering imposing an age limit to indoor tanning, similar to present controls on alcohol and tobacco.

In the United States, the maximum exposure time in most tanning beds is 20 minutes but varies from bed to bed. This is calculated by the manufacturer according to the amount of time needed to produce 4 MEDs (minimal erythemal doses). This is essentially 4 times the amount of UV that is required to produce a reddening on unexposed skin. A person would start with a much shorter session time and work their way to the maximum exposure time in about 4 weeks. Every tanning bed is required to have a "Recommended Exposure Schedule" on both the front of the tanning bed and in the owner's manual. It must also list the original lamp that was certified for that particular tanning bed, and salon owners must replace the lamps with either the exact same lamp, or a lamp that is certified by the lamp manufacturer to be legally equivalent. Lamp replacement and salon compliance is regulated by the individual state in the USA, whereas the manufacturing and sale of new equipment is regulated by the federal government.

Since many factors can change the performance of any given individual lamp, the United States Food and Drug Administration requires that every tanning bed model is certified separately, and lamps themselves do not have MED ratings. Lamps do have typical TE (or Time Exposure) ratings, but these are not used for certifying beds. Session times on beds can range from 5 minutes to 20 minutes, depending on many factors. In 2010, an FDA panel recommended banning the use of tanning beds for people under 18 years old.

In the United Kingdom anyone under 18 years of age will be banned from using sunbeds, as this legislation was passed by Parliament

Teaching reasonable behaviour is the supreme issue. Recommended protective measures in the order of their effectiveness are protection by adaptation of 
behaviour, by clothes, sun hats and sunglasses as well as by sun creams. Children are the most important target group. With regard to UV tanning appliances it is recommended not to use artificial UV radiation for cosmetic purposes because of the related health risks.

\section{Conclusion}

There were many measurements; consultancy and education programmes have been carried out by Gazi Non-Ionizing Radiation Protection Center - GNRP since its foundation. A key element in linking the complexity of the radio frequency radiation exposure sources and patterns with the needs of epidemiology is a measure that is capable of monitoring individual exposure. GNRP prepares training programmes for workers and its work on the determination of occupational exposure levels is still on the way. To minimize the risk of adverse health effects, RF fields must be in compliance with the applicable guidelines. These are under the responsibility of governmental authorities, manufacturers and employers. Further studies using different configurations and methods will be very interesting. Many countries have now established occupational RF health protection standards or guidelines. Turkey has no occupational exposure limits yet. GNRP's studies on establishing Turkey's missing regulations are also on going.

Acknowledgements: Electromagnetic Field measurement devices used in this study were supplied by the grant from Gazi University Research Foundation, No: 31 / 2002-07. We would also like to thank Semih OZDEN for his helps in the measurement

Declaration of Interest: The authors report no conflicts of interest. The authors alone are responsible for the content and writing of the paper.

\section{References}

1. Geller AC, Colditz G, Oliveria S, Emmons K, Jorgensen C, Aweh GN, et al. Use of sunscreen, sunburning rates, and tanning bed use among more than 10000 US children and adolescents. Pediatrics. 2002;109(6):1009-14

2. Coskun S, Balabanli B, Canseven A, Seyhan N. Effects of Continuous and Intermittent Magnetic Fields on Oxidative Parameters In vivo. Neurochemical Research. 2009;34(2):238-43.

3. Canseven AG, Coskun S, Seyhan N. Effects of various extremely low frequency magnetic fields on the free radica processes, natural antioxidant system and respiratory burst system activities in the heart and liver tissues. Indian Journal of Biochemistry \& Biophysics. 2008;45(5):326-31.

4. Akay C, Canseven AG, Erdem O, Seyhan N. Effect of intermittent and continuous exposure to electromagnetic field on calcium and magnesium levels in serum, brain, liver and kidney tissues. Toxicology Letters. 2007;172:S112-S
5. Tohumoglu G, Canseven AG, Cevik A, Seyhan N. Formulation of ELF magnetic fields' effects on malondialdehyde level and myeloperoxidase activity in kidney using genetic programming. Computer Methods and Programs in Biomedicine. 2007;86(1):1-9.

6. Canseven AG, Seyhan N, Mirshahidi S, Imir T. Suppression of natural killer cell activity on Candida stellatoidea by a $50 \mathrm{~Hz}$ magnetic field. Electromagnetic Biology and Medicine. 2006;25(2):79-85.

7. Guler G, Seyhan N, Aricioglu A. Effects of static and 50 $\mathrm{Hz}$ alternating electric fields on superoxide dismutase activity and TBARS levels in guinea pigs. General Physiology and Biophysics. 2006;25(2):177-93.

8. Gueler G, Tuerkoezer Z, Seyhan N. Electric field effects on guinea pig serum: The role of free radicals. Electromagnetic Biology and Medicine. 2007;26(3):20723.

9. Gueler G, Turkozer Z, Tomruk A, Seyhan N. The protective effects of $\mathrm{N}$-acetyl-L-cysteine and epigallocatechin-3-gallate on electric field-induced hepatic oxidative stress. International Journal of Radiation Biology. 2008;84(8):669-80.

10. Gueler G, Tuerkoezer Z, Ozgur E, Seyhan N. Antioxidants alleviate electric field-induced effects on lung tissue based on assays of heme oxygenase-1, protein carbonyl content, malondialdehyde, nitric oxide, and hydroxyproline. Science of the Total Environment. 2009;407(4):1326-32.

11. Sirav B. Radio Frequency Radiation Sources, Standards / Guidelines of Countries and International Organizations, Turkey's Situation and Radiation Calculation of a Pilot Region, MSc thesis, Gazi University, Institute of Health Sciences, Department of Biophysics, (MSc thesis with the supervision of Prof. Dr. Nesrin Seyhan and co-supervisor Asst. Prof. Dr. Ayse G. Canseven), 2001, Ankara TURKEY.

12. Sirav B, Seyhan N. Radio frequency radiation (RFR) from $\mathrm{TV}$ and radio transmitters at a pilot region in Turkey. Radiation Protection Dosimetry. 2009;136(2):114-7.

13. Sirav Aral B. Effects of $900 \mathrm{MHz}$ and $1800 \mathrm{MHz} \operatorname{Rad}(1)$ io frequency radiation on blood-brain barrier, $\mathrm{PhD}$ thesis, Gazi University, Institute of Health Sciences, Department of Biophysics, (PhD thesis with the supervision of Prof. Dr. Nesrin Seyhan), 2008, Ankara TURKEY.

14. Ozgur E. Variation in Mobile Phone Radiation with Voices of Different Frequencies and Strengths, Effects on Tissue Hydroxyproline Level. Gazi University Health Sciences Institute Biophysics Department, (MSc thesis with the supervision of Dr. Göknur Güler), 2006, Ankara Turkey.

15. Tuysuz MZ. Determination of Mobile Phone Exposure Based RF Dosimetry by using FDTD Methods, MSc thesis, Gazi University Health Sciences Institute Biophysics Department, (MSc thesis with the supervision of Dr. Canseven A.G.), 2007, Ankara Turkey

16. Budak GG, Budak B, Oetuerk GG, Muluk NB, Apan A, Seyhan N. Effects of extremely low frequency electromagnetic fields on transient evoked otoacoustic emissions in rabbits. International Journal of Pediatric Otorhinolaryngology. 2009;73(3):429-36.

17. SCENIHR Report. European Commission - Health \& Consumer Protection Directorate - General, SCENIHR Possible effects of electromagnetic fields (EMF) on Human Health, 2007. http://ec.europa.eu/health/ph risk/committees/04 scenihr/d ocs/scenihr_o_007.pdf Last accessed on 10 August 2009. 
18. Bernhardt JH. Electrosmog, cellular phones, sunbeds etc. -adverse health effects from radiation? Health aspects of non-ionizing radiation, Bundesgesundheitsblatt Gesundheitsforschung Gesundheitsschutz. 2005 Jan;48(1):63-75.

19. ICNIRP. Guidelines for Limiting exposure to time varying electric, magnetic and electromagnetic fields (Up to 300 $\mathrm{GHz}$ ), International Commission on Non-Ionizing Radiation Protection, Health Physics. 1998, 74(4): 494522

20. ICTA. Information and Communication Technologies Authority, 2001, Turkey, www.tk.gov.tr Last accessed on 10 August 2009.

21. IARC. Monographs on the Evaluation of Carcinogenic Risks to Humans, Volume 80, Non-Ionizing Radiation, Part 1: Static and Extremely Low-Frequency (ELF) Electric and Magnetic Fields, 2002, IARC Press, Lyon, France.

22. Kheifets L, Shimkhada R. Childhood Leukemia and EMF: Review of the Epidemiologic Evidence. Bioelectromagnetics Supplement, 2005, 7:S51-S59.

23. Health Physics Society Report, Ultraviolet radiation and public health, $\quad$ Feb 2007; http://www.hps.org/documents/ultraviolet_ps011-1.pdf.

24. IARC Working Group. The association of use of sunbeds with cutaneous malignant melanoma and other skin cancers: a systematic review. Int J Cancer 2006; 120: $1116-22$
25. Seddon JM, Gragoudas ES, Glynn RJ, Egan KM, Albert DM, Blitzer PH. HOST FACTORS, UV-RADIATION, AND RISK OF UVEAL MELANOMA - A CASECONTROL STUDY. Archives of Ophthalmology. 1990;108(9):1274-80.

26. El Ghissassi F, Baan R, Straif K, Grosse Y, Secretan B, Bouvard V, et al. A review of human carcinogens - Part D: radiation. Lancet Oncology. 2009;10(8):751-2.

27. Armstrong BK, Kricker A. The epidemiology of UV induced skin cancer. Journal of Photochemistry and Photobiology B-Biology. 2001;63(1-3):8-18.

28

Sinha RP, Hader DP. UV-induced DNA damage and repair: a review. Photochemical \& Photobiological Sciences. 2002;1(4):225-36

29. Nita S. Agar, Gary M. Halliday, Ross StC. Barnetson,Honnavara N. Ananthaswamy, Mark Wheeler, and Alexandra M. Jones. PNAS April 6, 2004;101(14):4954-59.

30. Fisher GJ, Wang ZQ, Datta SC, Varani J, Kang S, Voorhees JJ. Pathophysiology of premature skin aging induced by ultraviolet light. New England Journal of Medicine. 1997;337(20):1419-28.

Copyright (C) 2014 The Author(s); This is an open-access article distributed under the terms of the Creative Commons Attribution License (http://creativecommons.org/licenses/by/4.0), which permits unrestricted use, distribution, and reproduction in any medium, provided the original work is properly cited. All Rights reserved by international journal of Natural Science and Discovery 